\title{
A Broadband and High Gain Tapered Slot Antenna for W-Band Imaging Array Applications
}

\author{
Dong Sik Woo, Kang Wook Kim, and Hyun-Chul Choi \\ The School of Electronics Engineering, Kyungpook National University, Sankyuk-dong, Buk-gu, Daegu 702-701, Republic of Korea \\ Correspondence should be addressed to Hyun-Chul Choi; hcchoi@ee.knu.ac.kr
}

Received 29 July 2014; Accepted 5 October 2014; Published 23 November 2014

Academic Editor: Dau-Chyrh Chang

Copyright (C) 2014 Dong Sik Woo et al. This is an open access article distributed under the Creative Commons Attribution License, which permits unrestricted use, distribution, and reproduction in any medium, provided the original work is properly cited.

\begin{abstract}
A broadband and high gain tapered slot antenna (TSA) by utilizing a broadband microstrip- (MS-) to-coplanar stripline (CPS) balun has been developed for millimeter-wave imaging systems and sensors. This antenna exhibits ultrawideband performance for frequency ranges from 70 to over $110 \mathrm{GHz}$ with the high antenna gain, low sidelobe levels, and narrow beamwidth. The validity of this antenna as imaging arrays is also demonstrated by analyzing mutual couplings and 4-element linear array. This antenna can be applied to mm-wave phased array, imaging array for plasma diagnostics applications.
\end{abstract}

\section{Introduction}

The demand of wireless wideband communications is rapidly increasing due to the need to support more users and to provide more information with higher data rates. Wideband antennas are essential for providing wireless wideband communications. Many wireless, wideband communication devices require features of low-profile, linear polarization, and unidirectional patterns in a compact size [1]. TSA is a planar end-fire antenna and is often used for microwave/millimeter-wave imaging, sensors, and phased arrays [2]. It exhibits many advantages such as broad bandwidth, high gain, narrow beamwidth, and symmetrical radiation patterns. The TSA has many design parameters such as feeding balun structure, taper profile, taper length and the width of aperture, and shape of corrugations [35]. In order to feed the broadband TSA, several types of balun or transition have been reported in the literatures. However, unfortunately, conventional planar baluns such as MS-to-slotline, MS-to-CPS, coplanar waveguide- (CPW-) toslotline, and double $\mathrm{Y}$ impose limits on frequency bandwidth and radiation performances [6-9].

In this paper, a broadband and high performance TSA for $\mathrm{mm}$-wave imaging array application is presented. By using an ultrawideband MS-to-CPS balun [10], radiation parameters are very flat and uniform for whole $\mathrm{W}$-band frequencies due to good amplitude and phase imbalance of the balun. The overall antenna performances are analyzed by utilizing the commercial 3-dimensional electromagnetic simulators. Its possibilities to the $\mathrm{mm}$-wave imaging sensor arrays are also investigated by analyzing the mutual coupling and the radiation patterns of 4-element arrays.

\section{Balun and Antenna Design}

The design of the TSA is performed with simple two steps: (1) design of the balun and feed structure offering wide impedance bandwidth and (2) design of the CPS-fed TSA with the required radiation performances over operating frequency range. Firstly, for designing an ultrawideband MSto-CPS balun, the design procedure in [10] is adopted as shown in Figure 1. This broadband balun provides excellent amplitude and phase balance for whole W-band frequencies. The characteristic impedance of the CPS line is about 130 with 5 mil gap between CPS strips and 30 mil strip width using a 10 mil Duroid $5880\left(\varepsilon_{r}=2.2, \tan \delta=0.0009\right)$ substrate. With the CPS length $\left(l_{\text {cps }}\right)$ of 180 mil and the transition length $\left(l_{\text {bal }}\right)$ of 130 mil, the simulated insertion loss per transition is less 

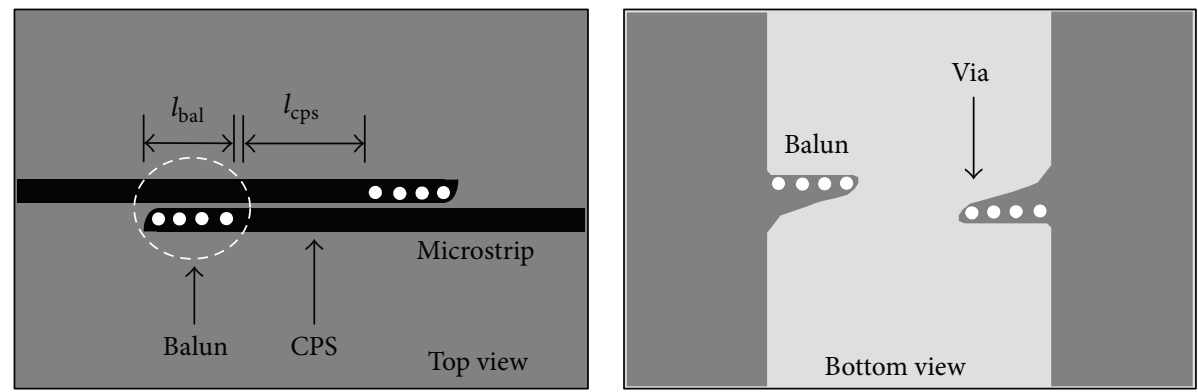

(a)

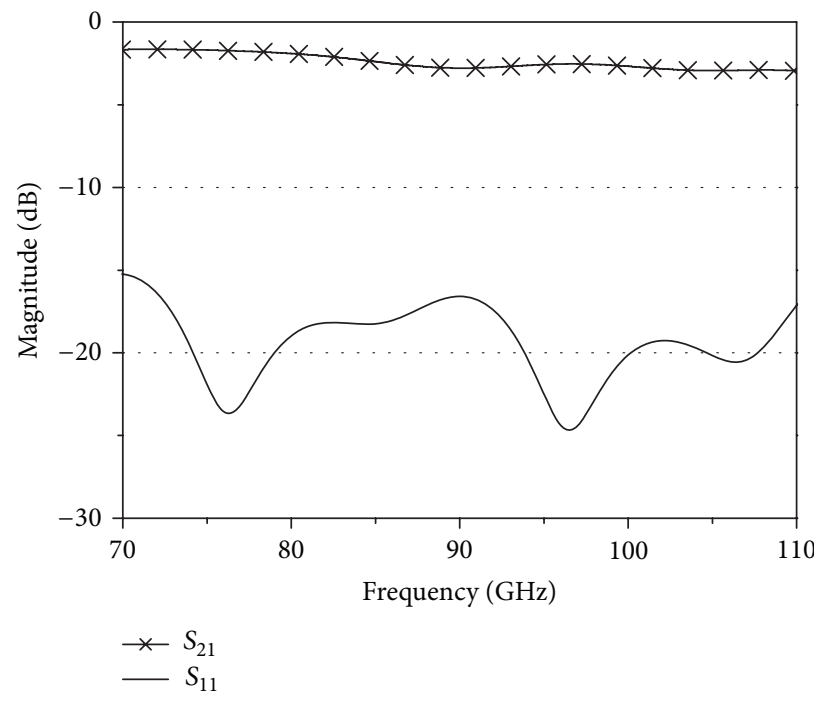

(b)

FIGURE 1: Microstrip-to-CPS balun: (a) layout and (b) simulated result. Balun dimensions (unit: $\mathrm{mm}$ ): $l_{\mathrm{bal}}=3.3$ and $l_{\mathrm{cps}}=2.29$ (via diameter is $0.5 \mathrm{~mm}$ ).

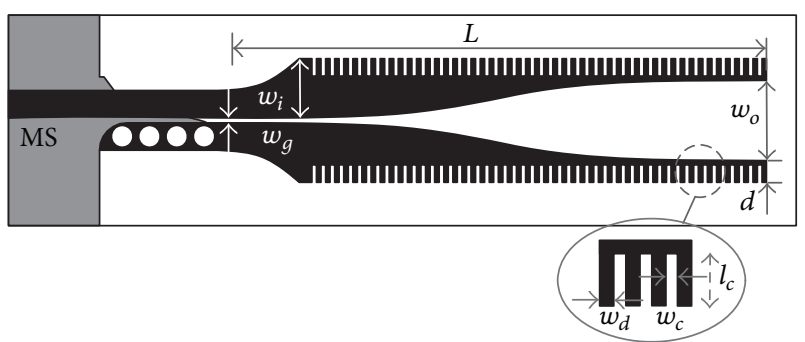

Figure 2: Geometry of the proposed antenna. Antenna dimensions (unit: $\mathrm{mm}$ ): $L=12.75\left(4 \lambda_{0}\right), w_{i}=1.63, w_{0}=2.24\left(0.7 \lambda_{0}\right), w_{g}=$ $0.13, d=0.61, w_{c}=w_{d}=0.13$, and $l_{c}=0.48$.

than $1.5 \mathrm{~dB}$ from 70 to over $110 \mathrm{GHz}$ as shown in Figure 1. Therefore, this broadband balun sufficiently covers whole frequency bandwidth of the ultrawideband TSA.

The TSA is designed and optimized at W-band frequencies. Figure 2 shows the geometry of proposed antenna and its detailed design parameters.
The proposed antenna consists of corrugated radiators and MS-CPS balun. A low permittivity substrate Duroid 5880 $\left(\varepsilon_{r}=2.2\right)$ with 10 mil thickness is utilized. The tapered radiators of the proposed TSA are governed with Fermi-Dirac tapering function $f(x)$. Antenna dimensions and parameters are calculated using the following equations:

$$
\begin{aligned}
f(x) & =\frac{a}{1+e^{-b(x-c)}} \\
b & =\frac{2.4}{\lambda_{0}} \\
c & =2 \lambda_{0},
\end{aligned}
$$

where $\lambda_{0}$ is free space wavelength at the center frequency, $a$ is the asymptotic value of the taper for $x$ approaches infinity, and $x$ is the variable of the taper length. The length of the antenna $(L)$ is chosen as $4 \lambda_{0}$ at $94 \mathrm{GHz}$. The opening width $w_{o}$ can be varied to obtain the desired radiation patterns and size. The value of $w_{o}$ is chosen as $0.7 \lambda_{0}$ as shown in Figure 2. The corrugation on upper and lower sides of the antenna is commonly used to suppress the surface-mode 


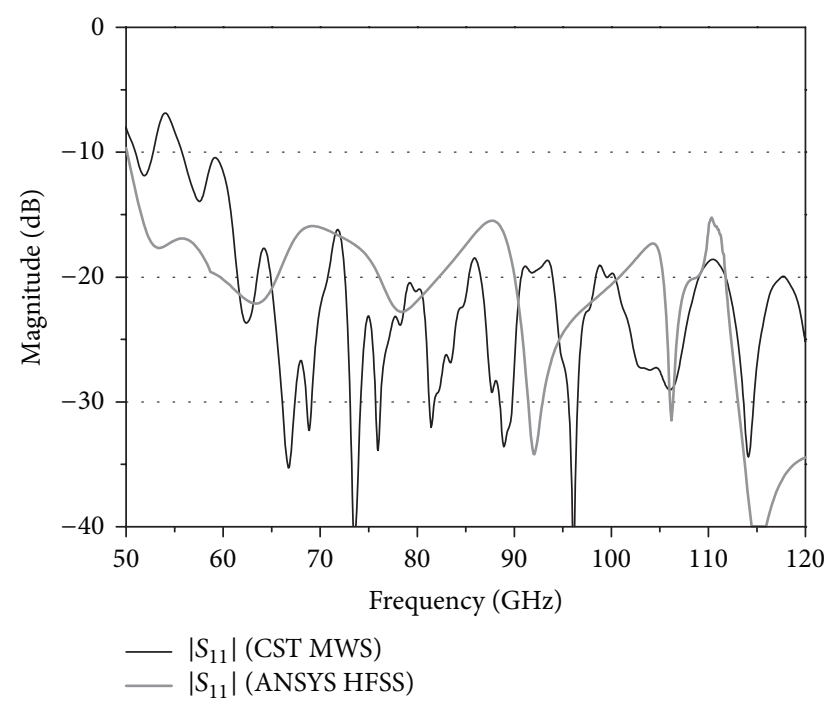

FIGURE 3: Simulated S-parameters of the antenna.

waves excited on the dielectric substrate and sidelobe level, to obtain higher gain, to improve the VSWR, and to widen the effective aperture size of antenna. The dimensions of the corrugation $\left(w_{c}, w_{d}, l_{c}\right)$ are chosen by [4] $\left(w_{c}=L / 100\right.$, $\left.l_{c}=0.15 \lambda_{0}\right)$. Finally, by connecting this MS-to-CPS balun to radiators, the TSA design is completed. The overall antenna size is $21.6 \times 5.6 \mathrm{~mm}$.

\section{Experimental Result}

The antenna is simulated with the CST Microwave Studio and cross-checked with the ANSYS HFSS. The simulated $S$-parameters demonstrates an ultrawideband performance, which is better than $10 \mathrm{~dB}$ return loss from 60 to over $110 \mathrm{GHz}$ as shown in Figure 3. The overall bandwidth of the antenna is almost the same as that of the broadband slotline-fed TSA radiators; that is, the CPS feed and the balun provide wide bandwidth and impedance matching so that there is no deviation in the bandwidth of the original broadband TSA.

For understanding the propagation characteristics of the antenna, surface current distributions $\left(J_{s}\right)$ are presented at frequencies 70,94 , and $110 \mathrm{GHz}$, respectively. The propagation behaviors are figured out along the open end. The transverse wave is also reduced by corrugations as shown in Figure 4.

The radiation performances of the single TSA are shown and summarized in Figure 5 and Table 1. The antenna gain maintains from 13 to $14 \mathrm{dBi}$ with low sidelobe levels of less than $-10 \mathrm{~dB}$ from 70 to $110 \mathrm{GHz}$. The $3 \mathrm{~dB}$ beamwidth ranges from $28^{\circ}$ to $34^{\circ}$ for E-plane and from $36^{\circ}$ to $39^{\circ}$ for $\mathrm{H}$ plane with good radiation efficiency (84 89\%). As can be seen, the gain, 3-dB beamwidth, sidelobe level, and efficiency variation are kept small and very uniform for whole operating frequency band due to good amplitude and phase balance of the feeding balun. The calculated group delay variation is within $1 \mathrm{~ns}$ as well with a large variation of about $2 \mathrm{~ns}$ at $96 \mathrm{GHz}$. From these results, it has been demonstrated that

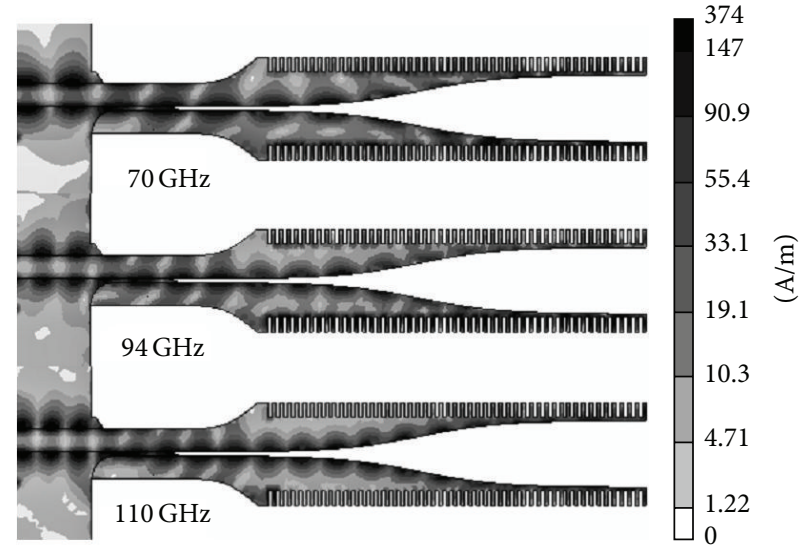

Figure 4: Surface current distributions at 70, 94, and $110 \mathrm{GHz}$.

TABLE 1: Performance summary of the proposed antenna.

\begin{tabular}{lccccc}
\hline & \multirow{2}{*}{ Gain [dBi] } & \multicolumn{2}{c}{$3 \mathrm{~dB}$ BW [degree] } & \multicolumn{2}{c}{ SLL [dB] } \\
& & E-plane & H-plane & E-plane & H-plane \\
\hline $70 \mathrm{GHz}$ & 13.6 & 33.6 & 38.6 & -17.6 & -14.7 \\
$94 \mathrm{GHz}$ & 13.7 & 28.2 & 36.5 & -15.5 & -11 \\
$100 \mathrm{GHz}$ & 14.1 & 27.6 & 37 & -17.4 & -10.7 \\
$110 \mathrm{GHz}$ & 13.9 & 28.7 & 38.4 & -15.2 & -8.6 \\
\hline
\end{tabular}

the proposed TSA is very suitable for all applications of broadband $\mathrm{mm}$-wave phased array and imaging systems.

\section{Antenna Array Analysis}

The TSA has some advantages as radiators for phased arrays, imaging arrays, and integrated active antennas because of the broad impedance bandwidth, symmetrical radiation pattern, and planar structure. In general, mutual coupling produces several effects including impedance mismatch, scanning blindness, and distortion of radiation patterns. The horizontal and vertical mutual coupling between two adjacent elements was investigated by calculating the transmission coefficient $S_{21}$ of two types of arrays. The center-to-center spacing between two configurations of the antennas is $140 \mathrm{mil}\left(1.1 \lambda_{0}\right)$ and $197 \mathrm{mil}\left(1.5 \lambda_{0}\right)$ at $90 \mathrm{GHz}$, respectively. The simulated horizontal and vertical mutual couplings are below $-20 \mathrm{~dB}$ and $-30 \mathrm{~dB}$ for whole $\mathrm{W}$-band frequencies as shown in Figure 6. From these results, it is clear that when the distance between two antennas is around $1 \sim 1.5 \lambda_{0}$, low mutual couplings can be achieved.

A 4-element equal-phase linear array is simulated to demonstrate the validity of the TSA as an array antenna element at $\mathrm{W}$-band as shown in Figure 7. The spacing between the antennas is chosen to be $1.1 \lambda_{0}$ at $90 \mathrm{GHz}$ for low sidelobe levels and small size. Figure 7 shows simulated radiation patterns of E-plane at 70, 94, and $110 \mathrm{GHz}$, respectively. The 


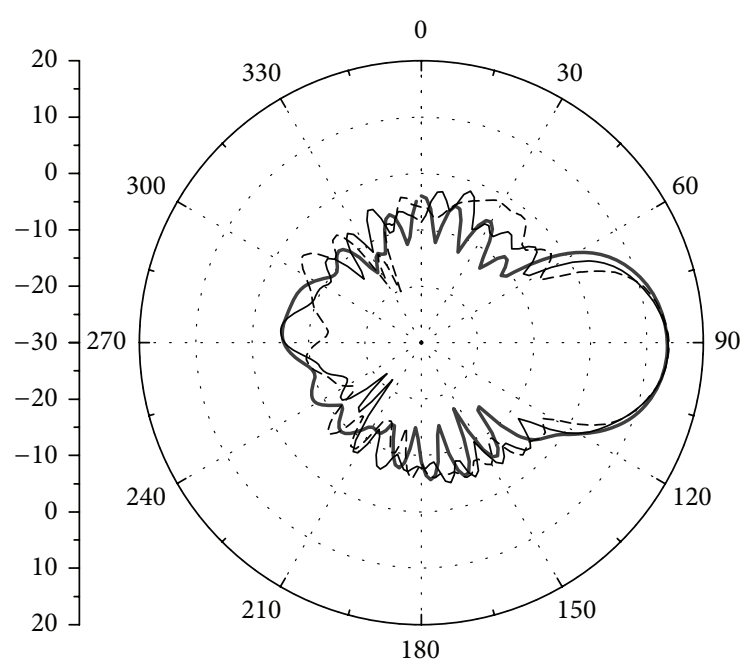

$-70 \mathrm{GHz}(\mathrm{dB})$
$-94 \mathrm{GHz}(\mathrm{dB})$
$---110 \mathrm{GHz}(\mathrm{dB})$

(a)

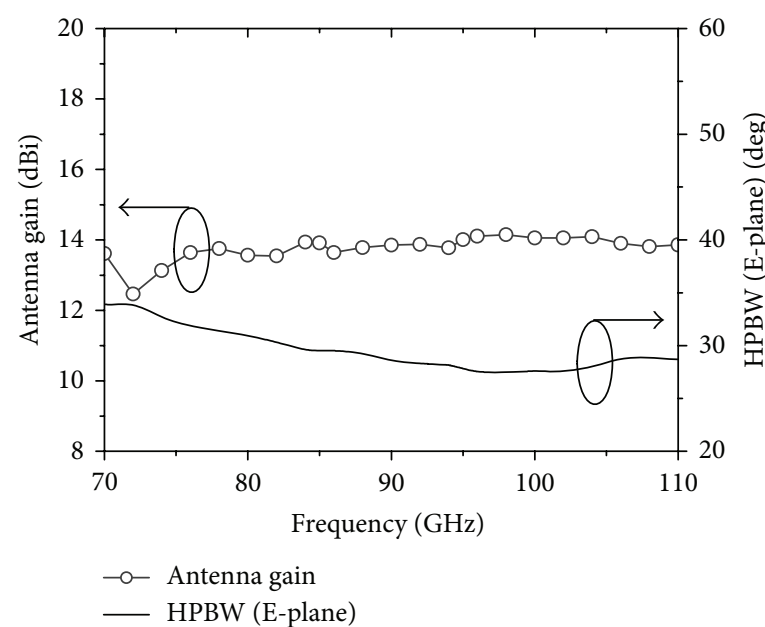

(c)

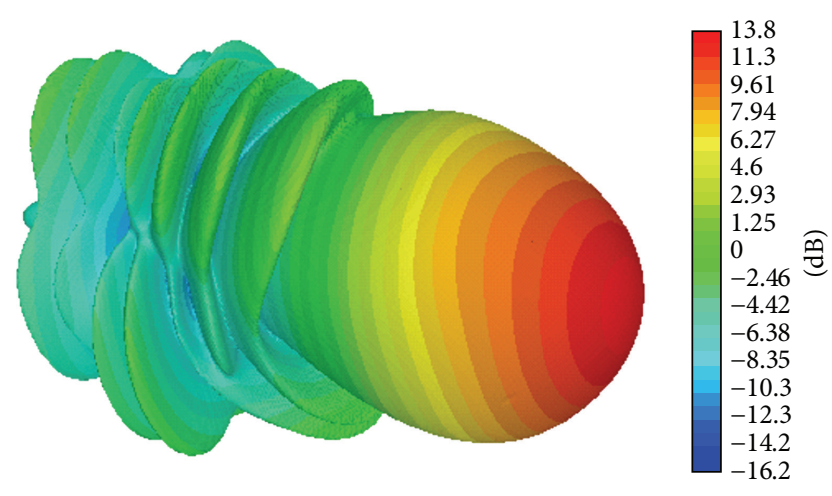

(b)

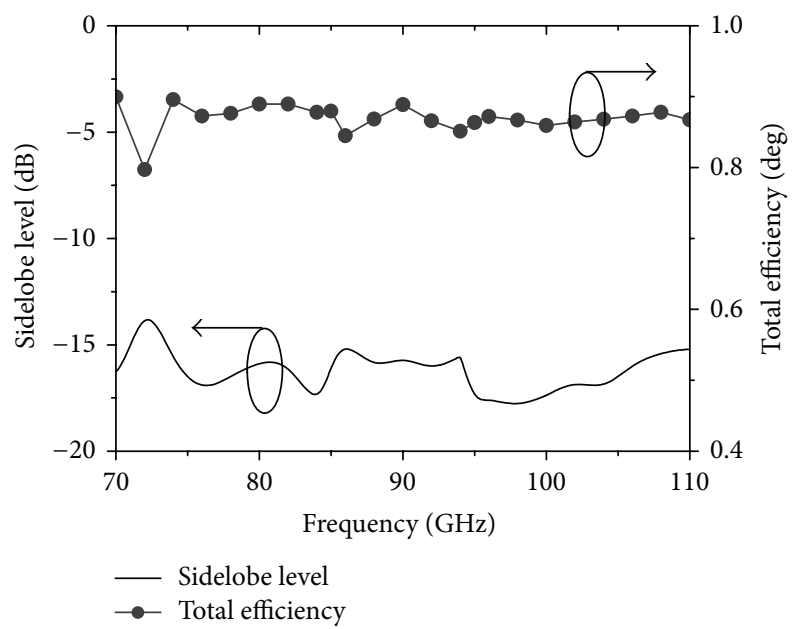

(d)

FIGURE 5: Simulated radiation performances: (a) E-plane radiation patterns at 70, 94, and $110 \mathrm{GHz}$, (b) 3D radiation pattern at $94 \mathrm{GHz}$, (c) gain and HPBW of E-plane, and (d) sidelobe level and efficiency.

calculated results indicate excellent radiation properties over almost the whole range of relevant frequencies. The gain of the antenna is from 16 to $18 \mathrm{dBi}$ with narrow beamwidth of $8.8^{\circ}$ to $13.5^{\circ}$. The radiation patterns are uniform for whole operation frequencies with low sidelobe levels. The maximum sidelobe level is about $-13.5 \mathrm{~dB}$. The overall dimension of 4element array antenna is only $21.6 \times 16 \mathrm{~mm}$.

\section{Conclusion}

This paper presents a design of broadband high gain $\mathrm{W}$-band TSAs for mm-wave phased array and imaging sensor applications. The proposed antenna consists of an ultrawideband
MS-to-CPS balun section and Fermi-Dirac tapered radiators with corrugation. Simulation results demonstrate high gain, symmetrical radiation patterns, narrow beamwidth, and low sidelobe levels for whole frequency ranges from 70 to $110 \mathrm{GHz}$ and above. The proposed antenna can be scaled to various frequency bands for planar passive and active sensors and phased arrays. In addition, this may be found as very useful in wideband 2- and 3-dimensional plasma imaging diagnostics.

\section{Conflict of Interests}

The authors declare that there is no conflict of interests regarding the publication of this paper. 


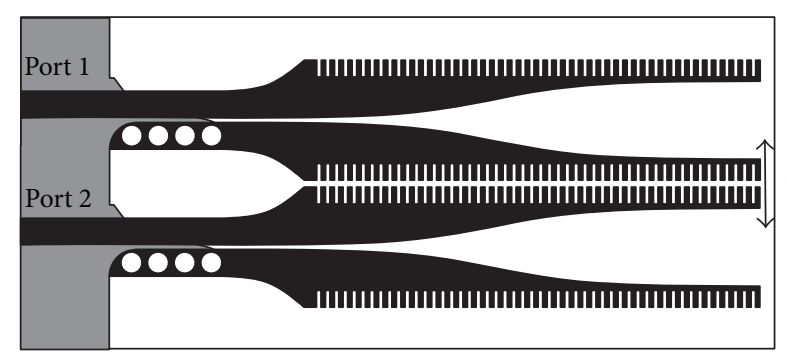

(a)

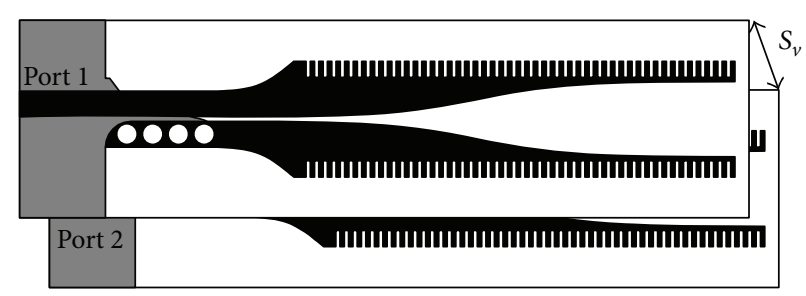

(b)

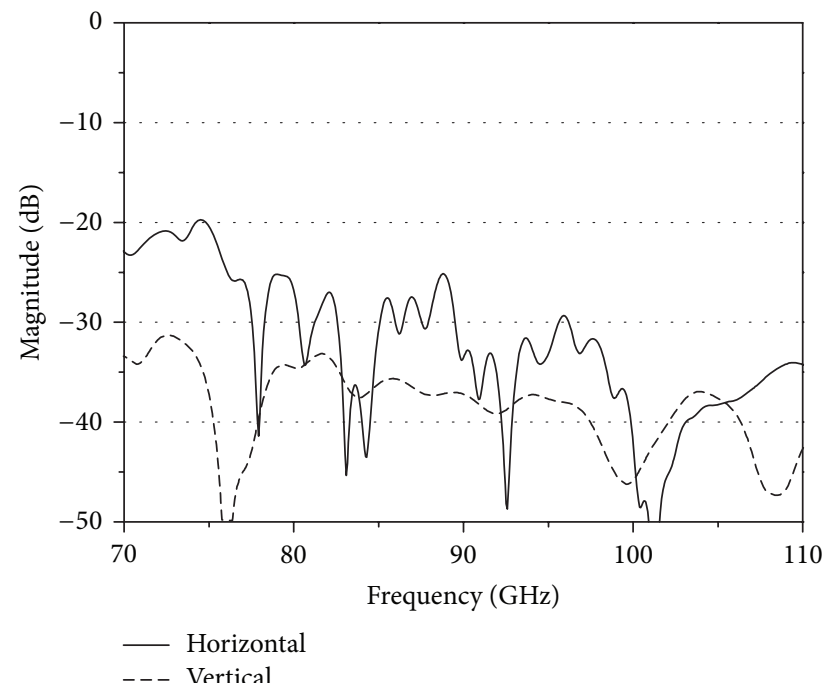

(c)

FIGURE 6: Two configurations of mutual couplings: (a) horizontal $\left(S_{h}=3.56 \mathrm{~mm}\right)$, (b) vertical $\left(S_{v}=5 \mathrm{~mm}\right)$, and (c) simulated mutual couplings $\left(S_{21}\right)$.
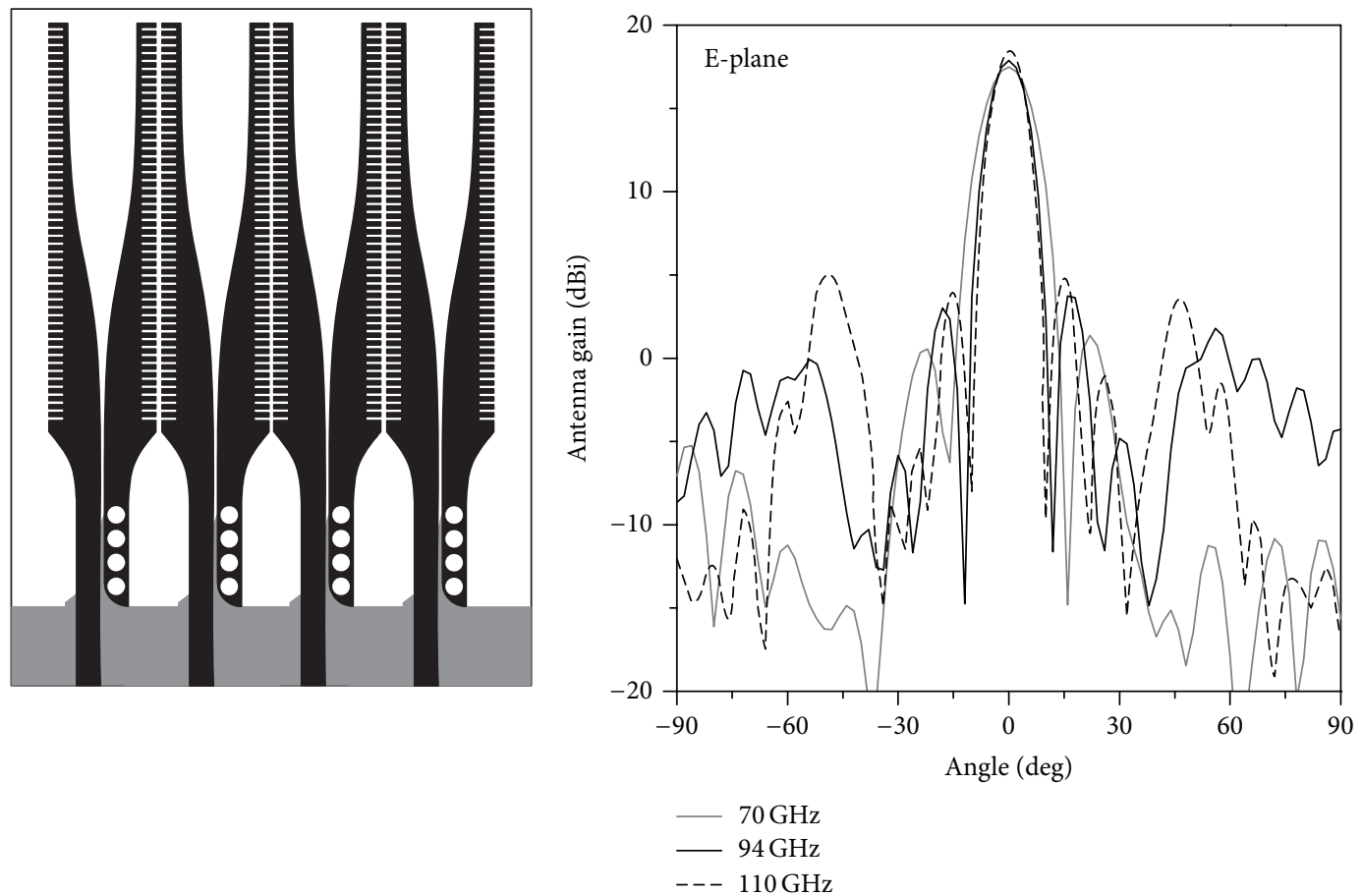

(a)

(b)

FIGURE 7: Four-element antenna array (a) geometry, (b) simulated E-plane radiation patterns at 70, 94, and $110 \mathrm{GHz}$. 


\section{Acknowledgments}

This research was supported by the MSIP (Ministry of Science, ICT and Future Planning), Korea, under the C-ITRC (Convergence Information Technology Research Center) support program (NIPA-2014-H0401-14-1004) supervised by the NIPA (National IT Industry Promotion Agency). This study was supported by the BK21 Plus project funded by the Ministry of Education, Korea (21A20131600011).

\section{References}

[1] J. D. Guha and Y. M. Antar, Microstrip and Printed AntennasNew Trends, Techniques and Applications, John Wiley \& Sons, New York, NY, USA, 2011.

[2] K. F. Lee and W. Chen, Advances in Microstrip and Printed Antennas, John Wiley \& Sons, New York, NY, USA, 1997.

[3] H. Sato, K. Sawaya, N. Arai, Y. Wagatsuma, and K. Mizuno, "FDTD Analysis of Fermi tapered slot antenna with corrugation structure," in Proceedings of the China-Japan Joint Meeting on Microwaves (CJMW'02), pp. 137-140, 2002.

[4] H. Sato, K. Sawaya, Y. Wagatsuma, and K. Mizuno, "Broadband FDTD design of fermi antenna for passive millimeter wave imaging," in Proceedings of the IEEE International Symposium on Microwave, Antenna, Propagation and EMC Technologies for Wireless Communications (MAPE'05), pp. 123-126, 2005.

[5] K. Sawaya, H. Sato, Y. Wagatsuma, and K. Mizuno, "Broadband FERMI antenna and its application to mm-wave imaging," in Proceedings of the 2nd European Conference on Antennas and Propagation (EuCAP'07), pp. 1-6, November 2007.

[6] R. N. Simons, N. I. Dib, R. Q. Lee, and L. P. B. Katehi, "Integrated uniplanar transition for linearly tapered slot antenna," IEEE Transactions on Antennas and Propagation, vol. 43, no. 9, pp. 998-1002, 1995.

[7] W.-H. Tu and K. Chang, "Wide-band microstrip-to-coplanar stripline/slotline transitions," IEEE Transactions on Microwave Theory and Techniques, vol. 54, no. 3, pp. 1084-1089, 2006.

[8] L. Yang, N. Ito, C. W. Domier, N. C. Luhmann Jr., and A. Mase, "18-40-GHz beam-shaping/steering phased antenna array system using fermi antenna," IEEE Transactions on Microwave Theory and Techniques, vol. 56, no. 4, pp. 767-773, 2008.

[9] K.-P. Ma, Y. Qian, and T. Itoh, "Analysis and applications of a new CPW-slotline transition," IEEE Transactions on Microwave Theory and Techniques, vol. 47, no. 4, pp. 426-432, 1999.

[10] Y.-G. Kim, D.-S. Woo, K. W. Kim, and Y.-K. Clio, "A new ultrawideband microstrip-to-CPS transition," in Proceedings of the IEEE MTT-S International Microwave Symposium (IMS'07), pp. 1563-1566, June 2007. 

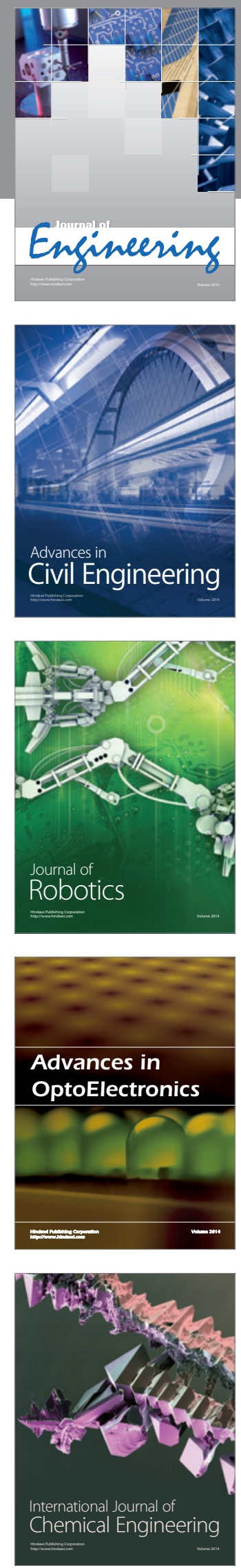

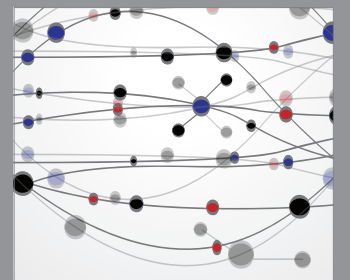

The Scientific World Journal
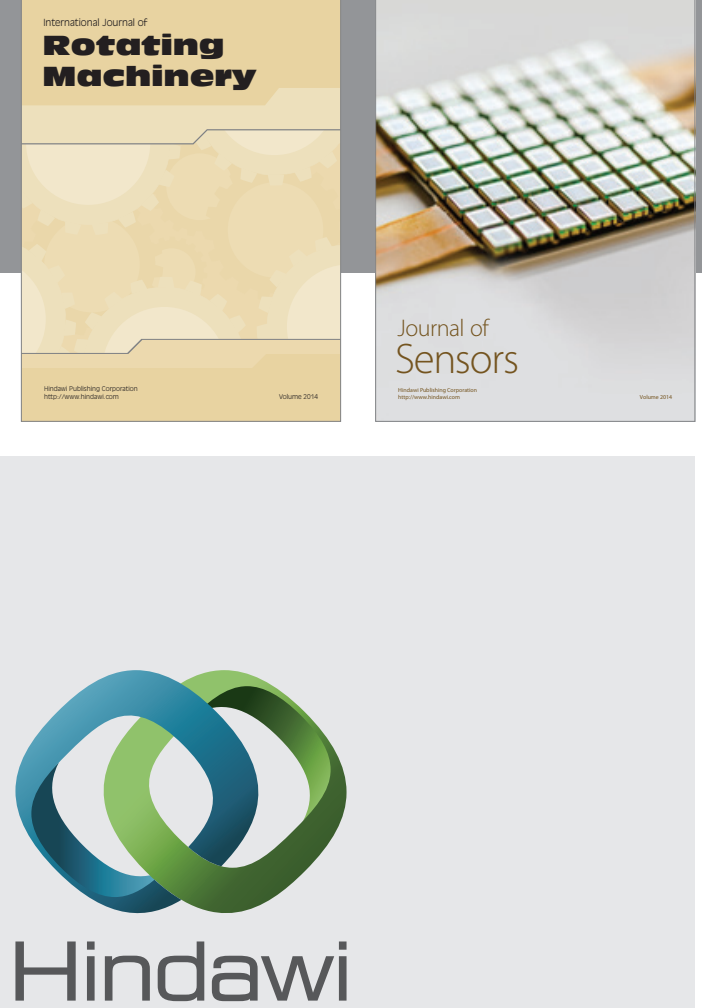

Submit your manuscripts at http://www.hindawi.com
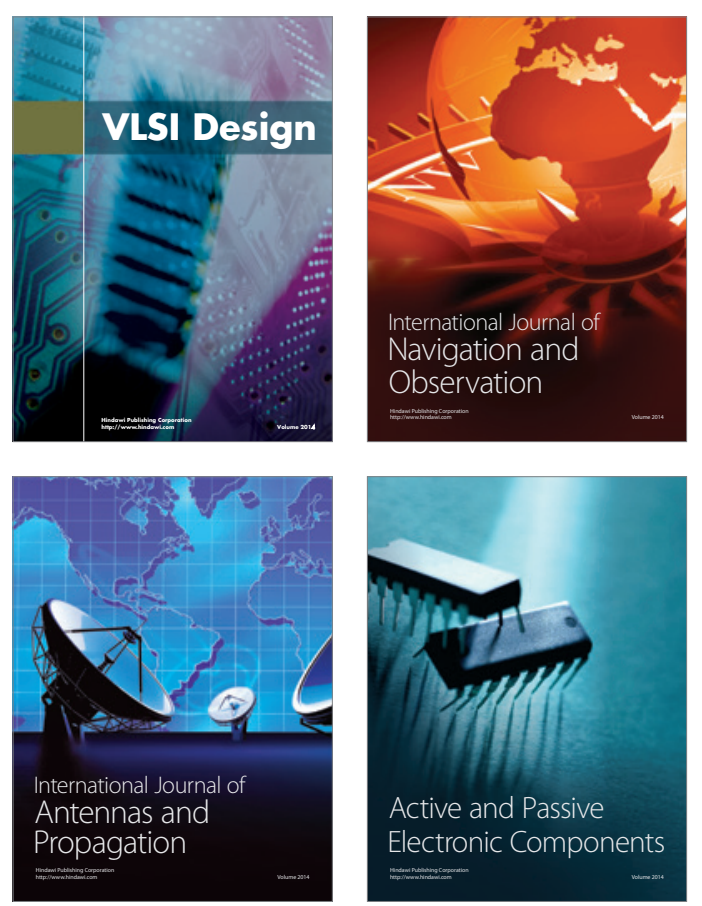
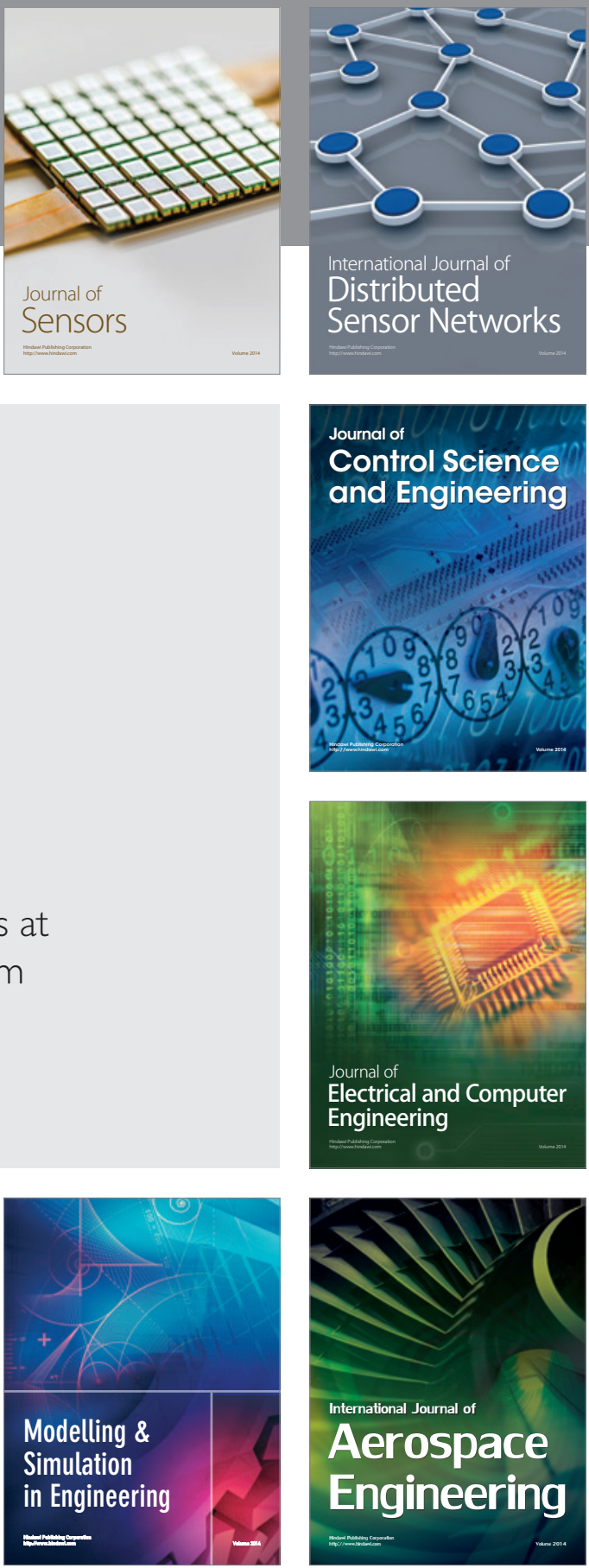

Journal of

Control Science

and Engineering
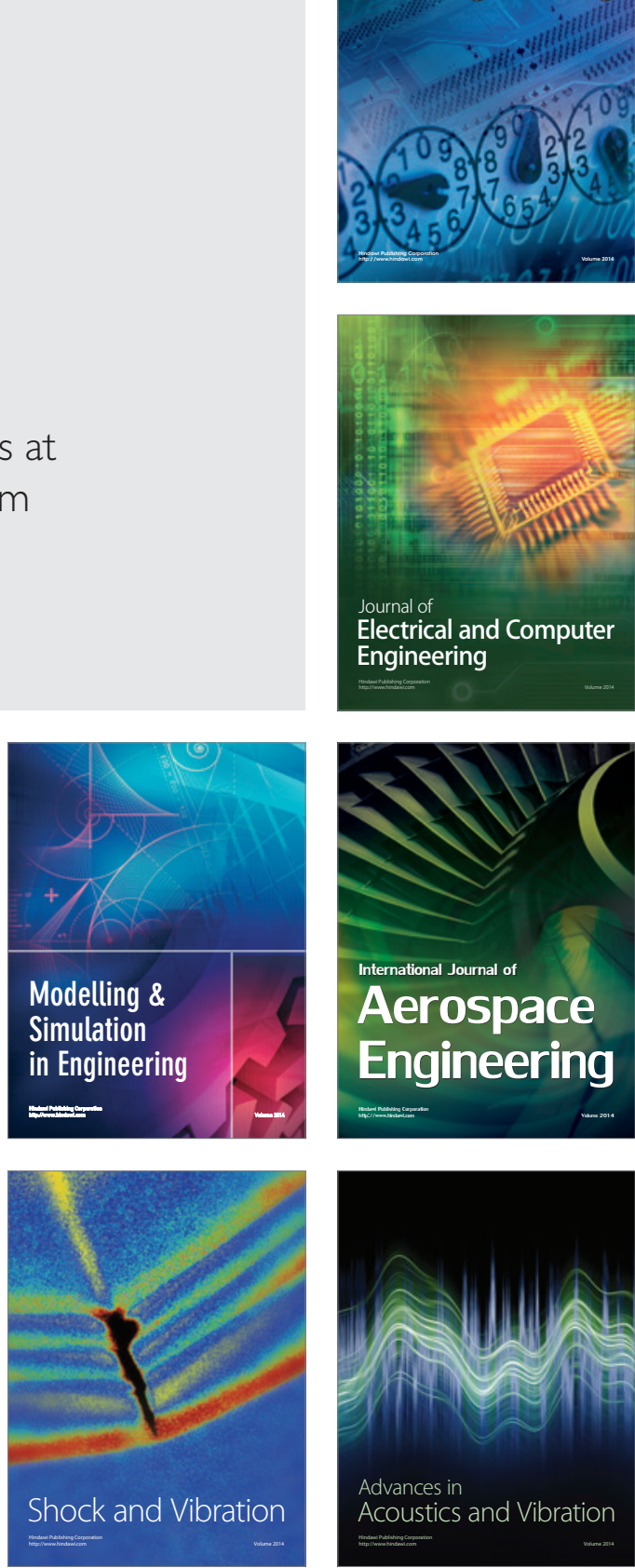